\title{
Visualization of Traditional Chinese Medicine Research in Recent 10 Years*
}

\author{
Zhonghui Yin \\ International Office \\ Hebei University of Chinese Medicine \\ Shijiazhuang, China \\ Jingyao Zhang \\ International Office \\ Hebei University of Chinese Medicine \\ Shijiazhuang, China
}

\author{
Lin Miao \\ International Office \\ Hebei University of Chinese Medicine \\ Shijiazhuang, China \\ Jiayi Fang \\ International Office \\ Hebei University of Chinese Medicine \\ Shijiazhuang, China
}

\begin{abstract}
In this article, the authors selected researches on traditional Chinese medicine (TCM) from the Web of Science Core Collection Database between the time span of 2007 and 2016. By using CiteSpace, the authors mainly visualized published items in each year, source titles, authors, institutions, countries and keywords so as to show the most important footprints of traditional Chinese medicine and offer some reference for researchers.
\end{abstract}

\section{Keywords-TCM; traditional Chinese medicine; CiteSpace}

\section{INTRODUCTION}

Speaking of the elements that best represent Chinese culture, $50 \%$ of the overseas respondents chose traditional Chinese medicine (TCM) [1]. In 2006, 67 Confucius Institutes dedicated their focus on traditional Chinese medicine, Chinese martial arts, etc [2]. TCM plays an important role all over the world. Most studies focus on the strategies and ways to help TCM be international. However, research should depend on a clear understanding of the problem. Few people offer an overall understanding of TCM research internationally.

This paper aims at seeking footprints of traditional Chinese medicine internationally in recent 10 years. The authors try to visualize and analyze published items in each year, source titles, authors, institutions, countries and keywords by CiteSpace.

\section{DATA AND METHODS}

\section{A. Data Collection}

In this research, we selected data from Web of Science Core Collection Database. Owning extensive databases such as Science Citation Index Expanded, Social Sciences Citation Index, Web of Science (WoS) is a good choice to collect related studies.

The Web of Science has several ways to search for bibliographic records. We chose basic search, which includes topic, author, and several other searchable fields. Enter "TCM or "traditional Chinese medicine" in Basic Search bar between the time span of 2007 and 2016. We retrieved 11,694 results from topic search. Save them to Other File Formats. Record content is "Full Record and Cited Reference". File Format is Plain Text. When you save the file, make sure the file name starts with the word 'download' and the file extension is .txt. [3]

\section{B. Visualization Tool}

CiteSpace, a visualization tool made by CHEN chaomei was applied in this research. Ibrahim Musa, Lecturer at Sudan University of Science and Technology said: CiteSpace is software for visualizing, and analyzing bibliometric data. Therefore, it is used in Domain Map Analysis, Bibliometric Analysis, and Scientometrics. It can also be used to help researchers find research topics and write their literature review. [4]. CiteSpace has become one of the most popular citation analysis and visualization software for its priorities in clarity and interpretability of visualization [5]. In this article, we used CiteSpace version of 5.1.R1.SE.5.20.2017.

\section{RESULTS AND ANALYSIS}

\section{A. Publication Years}

According to results analysis of WOS, we got record count in Each Year in "Fig. 1".

*The Project Supported by Youth Fund of Hebei University of Chinese Medicine (QNS2017008) and Educational and Teaching Reform Task of Hebei University of Chinese Medicine (17yb-30). 


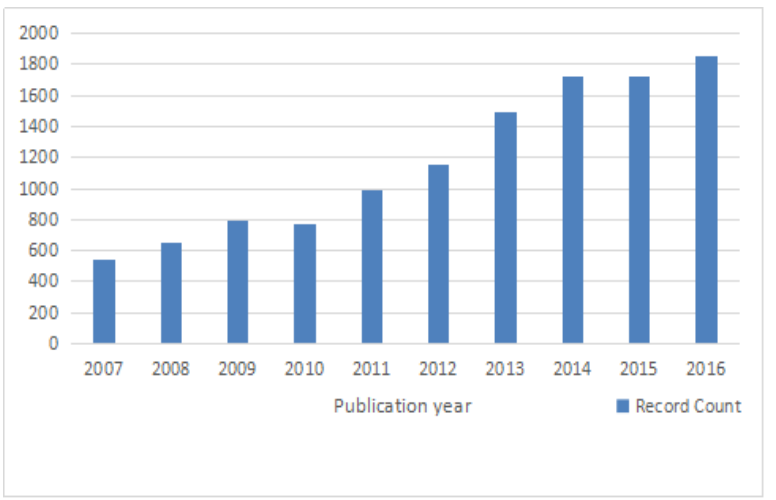

Fig. 1. Published Items in Each Year.

The results show that it is about TCM on the rise in general over the past 10 years. From 2007 to 2010, it increased in a wave-like manner. And there was an obvious growth from 2010 to 2014

\section{B. Source Titles}

Rank the records by source titles, analysis data from WOS shows that 11,694 papers were published in 2,219 journals. The Top 10 can be seen in "Fig. 2".

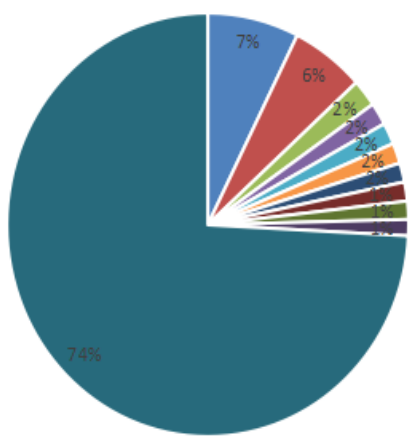

- JOURNAL OF ETHNOPHARMACOLOGY

- EVIDENCE BASED COMPLEMENTARY AND ALTERNATIVE MEDICINE
PLOSONE

- JOURNAL OF PHARMACEUTICAL AND BIOMEDICAL ANAL YSIS
JOURNAL OF TRADITIONAL CHINESE MEDICINE - AMERICAN JOURNAL OF CHINESE MEDICINE - JOURNAL OF SEPARATION SCIENCE - NEURAL REgENERATION RESEARCH - BMC COMPLEMENTARY AND ALTERNATIVE - MEDICINE

Fig. 2. TOP 10 source titles.

The top ranked source titles are JOURNAL OF ETHNOPHARMACOLOGY with records of 860 papers, account for $7.354 \%$ of 11,694. EVIDENCE BASED COMPLEMENTARY AND ALTERNATIVE MEDICINE and PLOS ONE are the second and third journals with records of 691 and 245 respectively. The top 10 ranked source titles account for $25.832 \%$ of 11,694 , with records of 3,021 .

\section{Authors}

Selected "Author" in the Node Types panel and unselected other node types. Set the timespan as "2007-2016" with 1-year slice. Top $\mathrm{N}=50$. CiteSpace read the data files and reported its progress in the two windows on the left-hand side of the user interface. Bibliographic networks can be very dense with many links. Selected Minimum Spanning Treto method removes excessive links systematically. Chose "Visualize" when the modeling process was completed [3].The result was
$\mathrm{N}=323, \mathrm{E}=595$ in "Fig. 3", which means there are 323 authors and 595 collaborated group in this conditions.

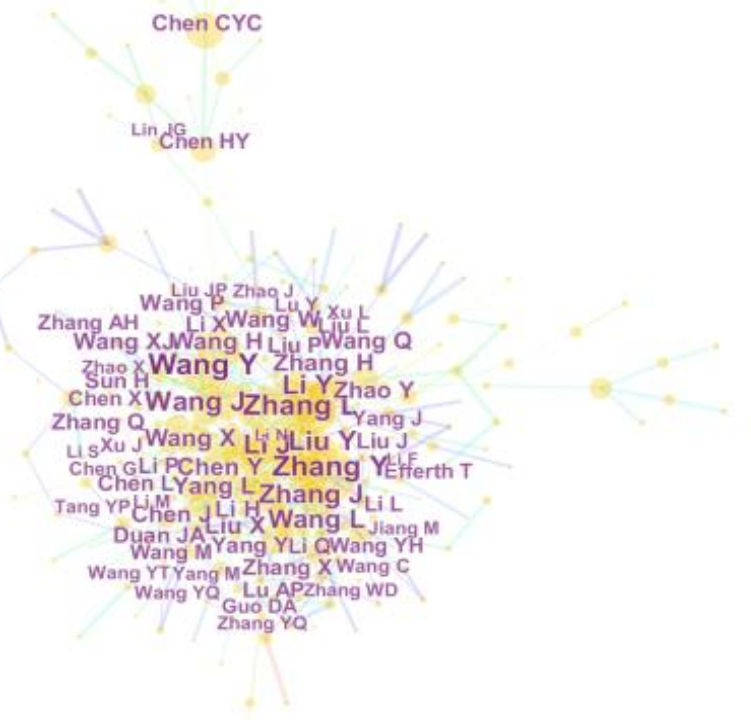

Fig. 3. Authors.

"Fig. 3" shows that authors collaborated frequently. The size of node is proportional to the record of papers. The bigger node size, the more papers the authors have. Wang $\mathrm{Y}$ ranks first with 244 papers. The second one is Zhang Y with 199 papers. And the third is Zhang L with 187 papers. 595 collaborations occurred.

According to Price Law ( $\left.\mathrm{N}=0.749 \mathrm{nmax} \frac{1 / 2}{2}\right)$ [6], $\mathrm{N}$ refers to core authors, and nmax refers to the records count of the most productive author. So $n \max =244, \mathrm{~N} \approx 16$. There are totally 83 core authors.

\section{Institutions}

Institution is also one important aspect of cooperation visualization. It is helpful for researchers to observe institutions with high influence by visualizing organizations. By selecting "Institution" as the node, using Minimum Spanning Treto, and pressing the Go! To start, we got 165 nodes and 376 lines, as "Fig. 4" showing.

Both of China Acad Chinese Med Sci and Chinese Acad Med Sci are the same institution. In order to combine them together, we right-clicked on the node China Acad Chinese Med Sci and selected it as the primary alias. Then rightclicked on the node Chinese Acad Med Sci and selected the secondary alias. Then we need to re-run the process to see the changes. 


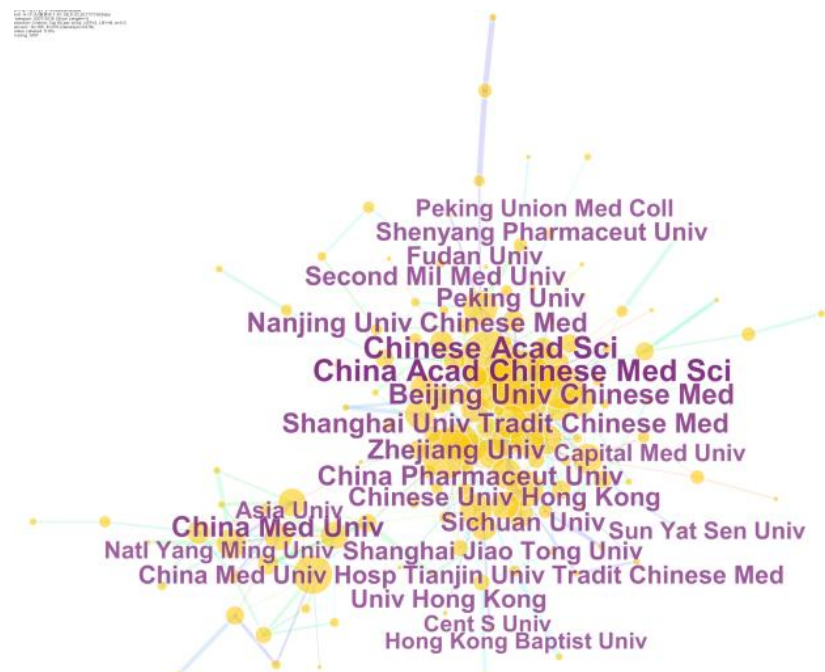

Fig. 4. Instructions.

TABLE I. TOP 10 INSTRUCTIONS

\begin{tabular}{|c|l|l|}
\hline Freq & \multicolumn{1}{|c|}{ Institutions } & \multicolumn{1}{|c|}{ Institutions-enhanced } \\
\hline $\mathbf{6 3 6}$ & $\begin{array}{l}\text { China Acad } \\
\text { Chinese Med Sci }\end{array}$ & $\begin{array}{l}\text { Chinese Academy of } \\
\text { Chinese Medical Sciences }\end{array}$ \\
\hline $\mathbf{5 6 4}$ & Chinese Acad Sci & $\begin{array}{l}\text { Chinese Academy of } \\
\text { Science }\end{array}$ \\
\hline $\mathbf{3 9 9}$ & China Med Univ & $\begin{array}{l}\text { Chinese Medical } \\
\text { University Taiwan }\end{array}$ \\
\hline $\mathbf{3 9 5}$ & $\begin{array}{l}\text { Beijing Univ } \\
\text { Chinese Med }\end{array}$ & $\begin{array}{l}\text { Beijing University of } \\
\text { Chinese Medicine }\end{array}$ \\
\hline $\mathbf{3 0 7}$ & $\begin{array}{l}\text { Shanghai Univ } \\
\text { Tradit Chinese Med }\end{array}$ & $\begin{array}{l}\text { Shanghai University of } \\
\text { Traditional Chinese } \\
\text { Medicine }\end{array}$ \\
\hline $\mathbf{2 7 0}$ & Zhejiang Univ & Zhejiang University \\
\hline $\mathbf{2 5 6}$ & $\begin{array}{l}\text { Nanjing Univ } \\
\text { Chinese Med }\end{array}$ & $\begin{array}{l}\text { Nanjing University of } \\
\text { Chinese Medicine }\end{array}$ \\
\hline $\mathbf{2 4 8}$ & $\begin{array}{l}\text { China Pharmaceut } \\
\text { Univ }\end{array}$ & $\begin{array}{l}\text { China Pharmaceutical } \\
\text { University }\end{array}$ \\
\hline $\mathbf{2 3 9}$ & Peking Univ & Peking University \\
\hline $\mathbf{2 1 8}$ & $\begin{array}{l}\text { Chinese Univ Hong } \\
\text { Kong }\end{array}$ & $\begin{array}{l}\text { The Chinese University of } \\
\text { Hong Kong }\end{array}$ \\
\hline
\end{tabular}

"Fig. 4" and "Table I" show that authors of different institutions collaborated frequently. There are totally 167 institutions with 376 collaborations. And all of the top 10 instructions came from China, including Taiwan and Hong Kong.

\section{E. Countries}

Visualizing countries help researchers understand which country studies TCM best. Select "Country" as the node type "Fig. 5", set the timespan as "2007-2016" with 1-year slice, and apply Minimum Spanning Treto method. Top N equals to 50. We got 63 nodes and 229 lines.

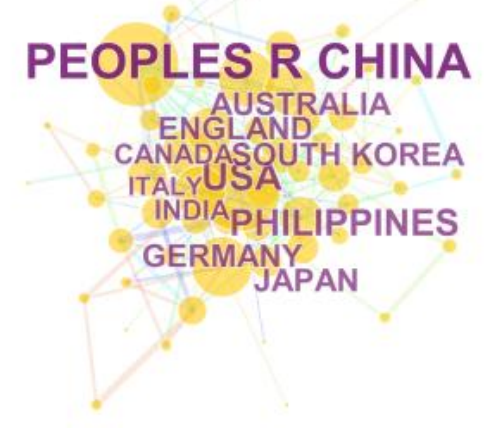

Fig. 5. Countries.

In the map PEOPLES R CHINA is the biggest node and rank the first with counts of 7,483 . The second country is USA with counts of 1,277 . The third is PHILIPPINES with counts of 821. The 4th is GERMANY with counts of 341 . The 5th is SOUTH KOREA with counts of 314 . The 6th is AUSTRALIA with counts of 258 . The 7 th is JAPAN with counts of 255 . The 8th is ENGLAND with counts of 250. The 9th is CANADA with counts of 168 . The 10th is INDIA with citation counts of 164.

\section{F. Keywords}

Keywords visualization is often used to analyze research hotpot and research trends. The frequency of keywords shows research hotpot while betweenness centrality of keywords shows research trends. Selected "Keyword" as the node type, set the timespan as "2007-2016" with 1-year slice, and applied Minimum Spanning Treto method. Top N=50. We got 111 nodes and 338 lines.

In the map, the bigger a node size is, the higher frequency it is. The bigger a fode size, the higher betweenness centrality it is. Combined with frequency and betweenness centrality of keywords, we found research foucs in recent 10 years (see "Fig. 6" ). 


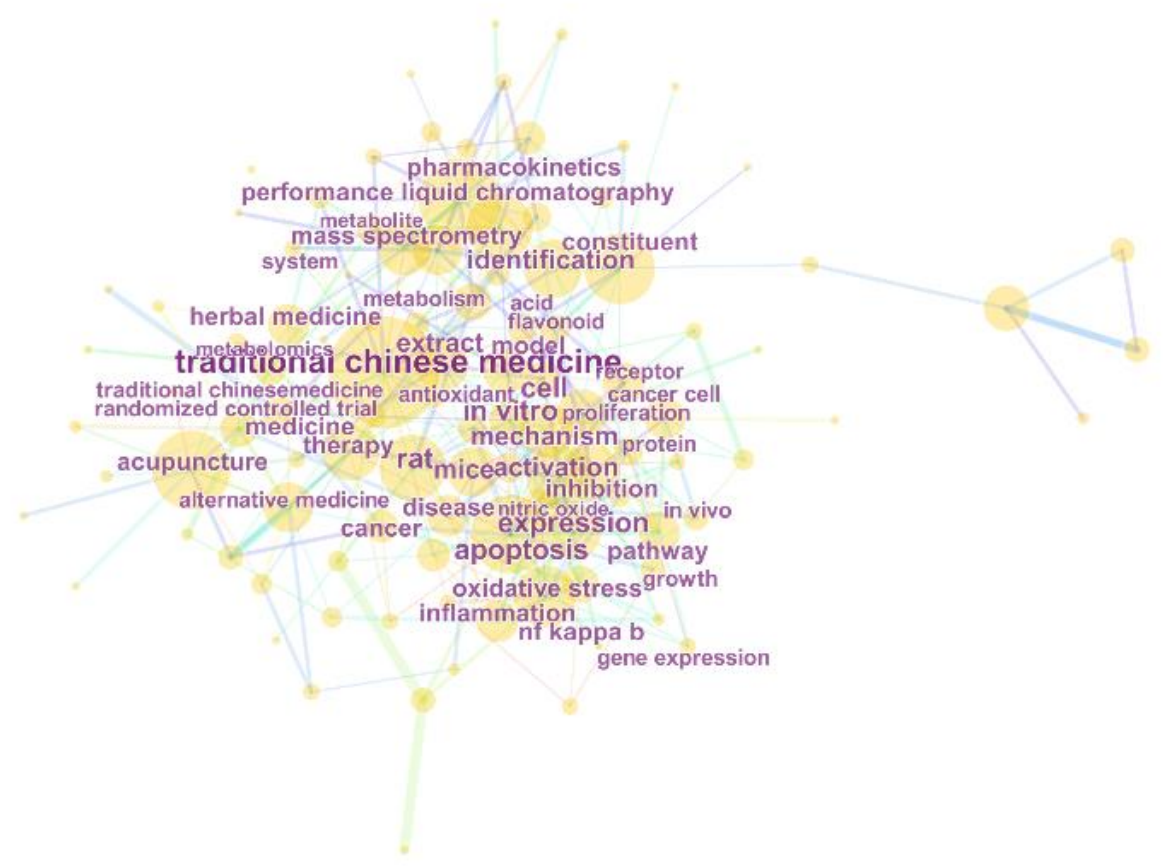

Fig. 6. Keywords.

TABLE II. TOP 20 KEYWORDS WITH HIGH FREQUENCY

\begin{tabular}{|c|c|c|c|}
\hline Freq & Keywords & Freq & Keywords \\
\hline 2431 & $\begin{array}{l}\text { traditional Chinese } \\
\text { medicine }\end{array}$ & 429 & identification \\
\hline 767 & expression & 395 & oxidative stress \\
\hline 756 & apoptosis & 386 & disease \\
\hline 729 & in vitro & 376 & $\begin{array}{l}\text { performance liquid } \\
\text { chromatography }\end{array}$ \\
\hline 718 & rat & 375 & mass spectrometry \\
\hline 673 & cell & 371 & inhibition \\
\hline 501 & activation & 351 & inflammation \\
\hline 478 & mice & 329 & Constituent \\
\hline 477 & extract & 327 & Therapy \\
\hline 431 & mechanism & 312 & Acupuncture \\
\hline
\end{tabular}

TABLE III. TOP 20 KEYWORDS WITH High CENTRALITY

\begin{tabular}{|c|l|c|l|}
\hline Centrality & \multicolumn{1}{|c|}{ Keywords } & Centrality & \multicolumn{1}{|c|}{ Keywords } \\
\hline $\boldsymbol{0 . 4 5}$ & $\begin{array}{l}\text { traditional } \\
\text { Chinese medicine }\end{array}$ & $\boldsymbol{0 . 1}$ & Oocyte \\
\hline $\mathbf{0 . 2 5}$ & identification & $\boldsymbol{0 . 1}$ & Separation \\
\hline $\boldsymbol{0 . 1 6}$ & $\begin{array}{l}\text { performance } \\
\text { liquid } \\
\text { chromatography }\end{array}$ & $\mathbf{0 . 0 9}$ & Extract \\
\hline $\mathbf{0 . 1 5}$ & constituent & $\mathbf{0 . 0 9}$ & Pharmacokinetics \\
\hline $\mathbf{0 . 1 5}$ & acupuncture & $\mathbf{0 . 0 8}$ & in vitro \\
\hline $\mathbf{0 . 1 3}$ & activation & $\mathbf{0 . 0 8}$ & Receptor \\
\hline $\mathbf{0 . 1 3}$ & culture & $\mathbf{0 . 0 7}$ & Model \\
\hline $\mathbf{0 . 1 2}$ & apoptosis & $\mathbf{0 . 0 7}$ & Proliferation \\
\hline $\mathbf{0 . 1 1}$ & therapy & $\mathbf{0 . 0 6}$ & Mice \\
\hline $\mathbf{0 . 1}$ & rate & $\mathbf{0 . 0 6}$ & oxidative stress \\
\hline
\end{tabular}

According to the data of keywords citations frequency and betweenness centrality, six aspects of "apoptosis, performance liquid chromatography, acupuncture, activation, oxidative stress, therapy" were the focus of TCM research. Keyword burst is an indicator of a most active area of research. It will show you fast growing topics. TCM research trend recently can be seen as "Table IV".

TABLE IV. TOP 10 KEYWORDS BURST

\begin{tabular}{|l|l|}
\hline Bursts & \multicolumn{1}{|c|}{ Keywords } \\
\hline 29.13 & quality control \\
\hline 26.63 & natural product \\
\hline 21.59 & plasma \\
\hline 21.25 & drug discovery \\
\hline 20.42 & induction \\
\hline 19.14 & hplc \\
\hline 18.55 & separation \\
\hline 18.45 & oocyte \\
\hline 18.44 & fertilization \\
\hline 16.78 & inhibitor \\
\hline
\end{tabular}

\section{CONCLUSION}

Visualizing publication years, authors, organizations, keywords from 11,694 papers about TCM, we conclude with a short summary.

We found an increase on researches about TCM from 2007 to 2016. An average of 1,169 papers were written a year. JOURNAL OF ETHNOPHARMACOLOGY, EVIDENCE BASED COMPLEMENTARY AND ALTERNATIVE MEDICINE and PLOS ONE are the top three journals.

For authors, Wang Y, Zhang Y, Zhang L and other 80 authors wrote most of the papers. Most of them were Chinese. For countries, China, USA, Philippines are the top 3. For institutions, Chinese Academy of Chinese Medical Sciences, Chinese Academy of Science, Chinese Medical University Taiwan and Beijing University of Chinese Medicine made the greatest fortune. Authors of different institutions collaborated 
frequently, and medical universities occupy most of the institutions. Six aspects of "apoptosis, performance liquid chromatography, acupuncture, activation, extract, oxidative stress, therapy" have been the focus of TCM research in recent 10 years, while, "quality control, natural product, plasma, drug discovery and induction" the fast growing topic.

\section{REFERENCES}

[1] 2015 China National Image Global Survey [EB/OL ], Centre for International Communication Studies, China, 2016, pp.18, http://www.chinacics.org/achievement/201609/P0201609225515356638 29.pdf.

[2] Confucius Institute Annual Development Report 2016 [ EB/OL], Confucius Institute Headquarters (Hanban), China, 2017, pp.1-2, http://www.hanban.org/report/index.html.

[3] Chen, Chaomei, The CiteSpace Manual [EB/OL ], USA, 2004 http://cluster.ischool.drexel.edu/ cchen/citespace/CiteSpaceManual.pdf.

[4] http://blog.sciencenet.cn/blog-554179-1058296.html.

[5] Chen, C., Searching for intellectual turning points: progressive knowledge domain visualization. Proc. Natl. Acad. Sci., USA, 2004, 101 (Suppl), pp.5303 - 5310 .

[6] Qiu Junping, Li Xingxing, Study on Knowledge Management Research Paper, Library, China, 2012, pp.71-74. 